\title{
Analysis of Polyphosphate during the Enhanced Biological Phosphorus Removal process using Fourier Transform Infrared (FTIR) spectroscopy
}

\author{
Rong wang ${ }^{1,2}$, Yuanyuan $\mathrm{Ma}^{1,2}$, Di Zhang ${ }^{1,2}$, Weihua $\mathrm{Li}^{1,2 *}$ \\ ${ }^{1}$ School of Environment and Energy Engineering, Anhui Jianzhu University, Hefei, Anhui 230601, China \\ ${ }^{2}$ Key Laboratory of Anhui Province of Water Pollution Control and Wastewater Reuse, Anhui Jianzhu University, Hefei, Anhui 230601, \\ China
}

\begin{abstract}
Two enhanced biological phosphorus removal (EBPR) reactors were operated in synthetic wastewater with different Chemical Oxygen Demand/Phosphorus (COD/P) ratios. The sludge samples at different sample times were lyophilized and characterized by Fourier Transform Infrared (FTIR) spectroscopy. Results showed that the infrared spectral curves from two reactors were similar but the intensities were different at specific wavenumbers. The spectral intensities at $1260 \mathrm{~cm}-1$ and $890 \mathrm{~cm}-1$ of the sludge samples from the reactor at low $\mathrm{COD} / \mathrm{P}$ ratios were relatively stronger, but those of the reactor at high COD/P ratios were relatively weaker. The principal component projection plot of FTIR spectra analyzed with principal components analysis (PCA) showed that the sludge samples at the same COD/P ratios assembled together implicating the principal component projection plot could discriminate the sludge samples from different reactor. The infrared peak near $890 \mathrm{~cm}-1$ was separated and integrated with Gaussian peak fitting method. The integrated areas were correlated to the polyphosphate content in the sludge. Results showed that the prediction values were in good accordance with those determined by chemical method. This work provides a new method for the recognition of polyphosphate in sludge and provides a basis for the rapid determination of polyphosphate.
\end{abstract}

\section{Introduction}

Enhanced biological phosphate removal (EBPR) process was economical efficient and environmental friendly, which became the key strategy in preventing eutrophication $^{[1]}$. Polyphosphate accumulating organisms (PAOs) was the main functional microorganism during the EBPR process, which could use the energy released by the polyphosphate (poly-P) hydrolization and reducing power by the glycolysis of glycogen to synthesize the polyhydroxy- $\beta$-alkonates (PHA). In the subsequent aerobic phase, PAOs use PHA as carbon source and energy for the cell growth, glycogen recovery and poly-P synthesis ${ }^{[2]}$.

However, another microorganism called glycogen accumulating organisms (GAOs) may accumulate during the anaerobic and aerobic alternating reactions. They decompose glycogen to acquire reducing power and energy, absorb the extracellular volatile fatty acids (VFAs) and synthesize the intracellular PHA storage during the anaerobicphase, and decompose intracellular PHA to realize cellular growth and glycogen recovery in the subsequent aerobic phase. They can compete with PAOs for carbon source and nutritious substance and do not contribute phosphate removal. Their bloom in the
EBPR process will result in the significant decline of phosphate removing effect or the collapse of EBPR process $^{[3]}$.

In the EBPR process, dominant population of PAOs in the activated sludge is ideal which means the good phosphate removing effect. The main difference between PAOs and GAOs is whether there is poly-P in the sludge. The analysis of poly-P in the activated sludge always relies on microscopy and chemical analysis. Neisser or 4',6-diamidino-2-phenylindole (DAPI) dye methods can be used to characterize the poly-P particles, while it can be used to characterize their existence and cannot be used to determinate the poly-P content in the cell ${ }^{[4]}$.

The quantification determination of poly-P relies on chemical analysis which transforms the ntracellular poly$\mathrm{P}$ into orthophosphate by perchloric and sulfuric acid and then determined with ammonium molybdate spectrophotometry ${ }^{[5,6]}$ However, the procedure of these methods are tedious and may induce some operation errors, which cannot acquire the intracellular poly-P in time.

Spectral analysis is a rapid and accurate method to analyze the intracellular poly-P in the activated sludge. Raman method was used to characterize the intracellular poly-P in the activated sludge ${ }^{[7]}$. When the polarizability varies with molecular vibration, the variation can be detected by Raman spectroscopy. FTIR spectroscopy is

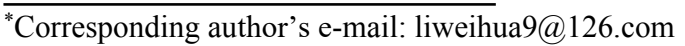


also originated from molecular vibration. When the dipole moment varies with molecular vibration, it will be detected with FTIR spectroscopy ${ }^{[8]}$. Thus, these two vibration spectra are complementary to some extent. Some information about the molecular structure can be acquired with FTIR spectroscopy.

The peak of Fourier transform infrared (FTIR) spectra was narrow and could reflect the information of different chemical bond. This method was rapid and accurate, which was the powerful tool to characterize the intracellular components. Based on the characteristic infrared absorption of the compound, the sample can be characterized qualitatively and semi-quantitatively. The infrared spectra of the cells of E. coli were acquired as well as intracellular poly- $\beta$-hydroxybutyrate (PHB) was determined using gas chromatography ${ }^{[9]}$.

The carboxyl absorption of PHB was located at 1735 $\mathrm{cm}-1$, and the correlation model between infrared spectra and intracellular PHB content was established by partial least squares (PLS) methods using the absorption of protein as inner standard ${ }^{[9]}$. In our previous study, the lyophilized sludge from EBPR reactor was characterized using FTIR spectra and intracellular PHA of the activated sludge was analyzed by the above methods ${ }^{[10]}$. However, to the best of my knowledge, there is no report about the quantification of poly-P in the sludge using FTIR spectroscopy.

In this work, the lyophilized sludge from different phosphate/carbon ratio reactors was characterized by FTIR spectroscopy. The characteristic absorption peak of poly-P was recognized and the spectral difference of two reactors was analyzed using projection plot with principal components analysis (PCA) ${ }^{[11]}$.

The infrared absorption peak of poly-P was separated using Gaussian peak fitting method and the integrated peak area was acquired. Combined with the analysis result of poly-P determined by chemical method, the correlation curve was established between the integrated infrared peak area and poly-P content. Furthermore, the spectra between $840 \mathrm{~cm}-1$ and $1200 \mathrm{~cm}-1$ were selected and the correlation model was established between the poly-P content and selected spectral data with PLS method. This study will provide the basis for the rapid recognition and quantification of poly-P in the activated sludge.

\section{Materials and methods}

\subsection{Reactor setup and operation}

The sequence batch reactor (SBR) of EBPR process was operated to accumulated PAOs and GAOs using synthetic wastewater at different Chemical Oxygen Demand/Phosphorous (COD/P) ratios respectively. The effective volume of the reactor is $4.0 \mathrm{~L}$. There is cycle every $8 \mathrm{~h}$, i.e. $10 \mathrm{~min}$ fill in, $120 \mathrm{~min}$ anaerobic mixing, $180 \mathrm{~min}$ aerobic treatment, $160 \mathrm{~min}$ idle and $10 \mathrm{~min}$ effluent. The influent volume of every cycle is $2.0 \mathrm{~L}$ and the hydraulic retention time is $16 \mathrm{~h} .400 \mathrm{~mL}$ of mixed liquor was wasted each day to keep the solids retention time (SRT) at 10 days.

\subsection{Synthetic feed}

The synthetic wastewater at low $\mathrm{COD} / \mathrm{P}$ ratios favoured the PAOs. The acetate was used as the sole carbon source for the synthetic phosphate-rich wastewater. $2.0 \mathrm{~L}$ influent was composed with $0.3 \mathrm{~L}$ solution $\mathrm{A}$ and $1.7 \mathrm{~L}$ solution B. The solution A was composed as following: $5.67 \mathrm{~g} / \mathrm{L} \quad \mathrm{NaAc} 3 \mathrm{H}_{2} \mathrm{O}, \quad 0.51 \mathrm{~g} / \mathrm{L} \quad \mathrm{NH}_{4} \mathrm{Cl}, 0.005 \mathrm{~g} / \mathrm{L}$ peptone, $0.005 \mathrm{~g} / \mathrm{L}$ yeast extract, $0.60 \mathrm{~g} / \mathrm{L} \mathrm{MgSO}_{4} 7 \mathrm{H}_{2} \mathrm{O}$, $0.095 \mathrm{~g} / \mathrm{L} \mathrm{CaCl}{ }_{2} 2 \mathrm{H}_{2} \mathrm{O}, 3.97 \mathrm{mg} / \mathrm{L}$ allylthiourea and 2.00 $\mathrm{mL}$ micro element solution. The micro element solution was composed as following: $1.5 \mathrm{~g} / \mathrm{L} \mathrm{FeCl}_{3} 6 \mathrm{H}_{2} \mathrm{O}, 0.15$ $\mathrm{g} / \mathrm{L} \mathrm{H} 3 \mathrm{BO} 3,0.03 \mathrm{~g} / \mathrm{L} \mathrm{CuSO}_{4} 5 \mathrm{H}_{2} \mathrm{O}, 0.18 \mathrm{~g} / \mathrm{L} \mathrm{KI}, 0.12$ $\mathrm{g} / \mathrm{L} \mathrm{MnCl}{ }_{2} 4 \mathrm{H}_{2} \mathrm{O}, 0.06 \mathrm{~g} / \mathrm{L} \mathrm{Na}_{2} \mathrm{MoO}_{4} 2 \mathrm{H}_{2} \mathrm{O}, 0.12 \mathrm{~g} / \mathrm{L}$ $\mathrm{ZnSO}_{4} 7 \mathrm{H}_{2} \mathrm{O}, \quad 0.15 \mathrm{~g} / \mathrm{L} \quad \mathrm{CoCl}_{2} \quad 6 \mathrm{H}_{2} \mathrm{O}$ and $10.0 \mathrm{~g} / \mathrm{L}$ elhylene diamine tetraacetic acid (EDTA). Solution $\mathrm{B}$ was composed with $66 \mathrm{mg} / \mathrm{L} \mathrm{K} 2 \mathrm{HPO} 4$ and $51.5 \mathrm{mg} / \mathrm{L}$ $\mathrm{KH}_{2} \mathrm{PO}_{4}{ }^{[12]}$. The chemical oxygen demand (COD) and orthophosphate of mixed influent was $400 \mathrm{mg} / \mathrm{L}$ and $20 \mathrm{mg} / \mathrm{L}$ respectively. Thus, the ratio of COD/P was 20:1.

The synthetic wastewater at high $\mathrm{COD} / \mathrm{P}$ ratio favoured the GAOs. Thus, the composition of synthetic wastewater was the same as above except for the concentration of phosphate. The solution $\mathrm{B}$ of the synthetic wastewater at low phosphate/carbon ratios was composed of $13.2 \mathrm{mg} / \mathrm{L}$ K2HPO4 and $10.3 \mathrm{mg} / \mathrm{L}$ $\mathrm{KH}_{2} \mathrm{PO}_{4}$, which results in the $4.0 \mathrm{mg} / \mathrm{L}$ orthophosphate concentration and the ratio of COD/P was 100:1.

\subsection{Monitoring of reactor performance}

After the influent was pumped into the bioreactor, the mixed liquor was sampled at $0 \mathrm{~min}, 30 \mathrm{~min}, 60 \mathrm{~min}, 90$ $\mathrm{min}, 120 \mathrm{~min}, 150 \mathrm{~min}, 180 \mathrm{~min}, 240 \mathrm{~min}$ and $300 \mathrm{~min}$ respectively. The samples were centrifuged at $12000 \mathrm{rpm}$ and the supernatants were analyzed to acquire COD and phosphate concentration. The activated sludge was harvested and lyophilized after washed, resuspended and centrifugated twice with normal saline to remove the growth medium.

\subsection{Analytical procedures}

The determination of poly-P was performed as following: 20-30 mg lyophilized sludge was washed three times with $0.5 \mathrm{mg} / \mathrm{L}$ perchlorate solution and then washed with $75 \%, 95 \%$ and $100 \%$ ethanol respectively. $10 \mathrm{~mL}$ of $1.0 \mathrm{~mol} / \mathrm{L}$ perchlorate was added and oscillated for $24 \mathrm{~h}$. Then it was centrifuged for $10 \mathrm{~min}$ and the supernatant was harvested. $10 \mathrm{~mL}$ of $0.5 \mathrm{~mol} / \mathrm{L}$ perchlorate was added to the sludge and oscillated at $90 \mathrm{oC}$ for $10 \mathrm{~min}$. The supernatant was also harvested and mixed with the previous one, and then diluted to $50 \mathrm{~mL}$. $2 \mathrm{~mL}$ solution was taken out and 2 drops of concentrated sulfuric acid were added and heated for $10 \mathrm{~min}$ at $100 \mathrm{oC}{ }^{[5,6]}$. After the solution was cooled to room temperature, the phosphate concentration was determined with ammonium molybdate spectrophotometry ${ }^{[13]}$. 
The FTIR spectra of the activated sludge were acquired with Thermofisher Nicolet 330 spectrometer. The spectra range was from $4000 \mathrm{~cm}^{-1}$ to $400 \mathrm{~cm}^{-1}$, the resolution was $0.5 \mathrm{~cm}^{-1}$, and 16 scans was added and averaged to acquire the final spectrum of the sample.

\section{Results and discussion}

\subsection{Profiles of COD and phosphorus concentration}

The profiles of COD, orthophosphate and poly-P of the reactor at low $\mathrm{COD} / \mathrm{P}$ ratio were shown in Fig. 1a. After the influent was pumped into the reactor, COD concentration was $200.6 \pm 12.0 \mathrm{mg} / \mathrm{L}$ and the orthophosphate concentration was $20.2 \pm 3.6 \mathrm{mg} / \mathrm{L}$. At the end of the anaerobic phase COD concentration decreased to $37.4 \pm 4.3 \mathrm{mg} / \mathrm{L}$ and orthophosphate concentration increased to $118.2 \pm 7.8 \mathrm{mg} / \mathrm{L}$, which implicated that acetate was consumed in the anaerobic phase and the poly-P was hydrolyzed and transformed to orthophosphate at the same time. During the aerobic phase COD concentration did not varied substantially, while orthophosphate decreased to $4.1 \pm 1.3 \mathrm{mg} / \mathrm{L}$ which implicated that orthophosphate was transformed to poly$\mathrm{p}$ and accumulated by the microorganism.
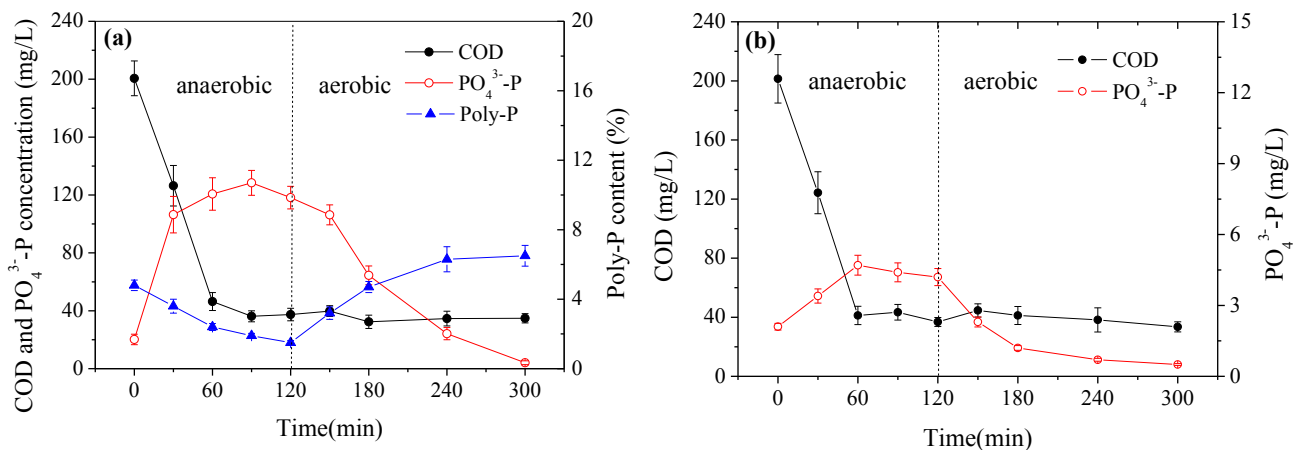

Fig. 1. Profiles of $\mathrm{COD}, \mathrm{PO}_{4}{ }^{3-}$ concentration and poly-P content during the anaerobic and aerobic cycle: (a) low $\mathrm{COD} / \mathrm{P}$ ratio wastewater; (b) high $\mathrm{COD} / \mathrm{P}$ ratio wastewater
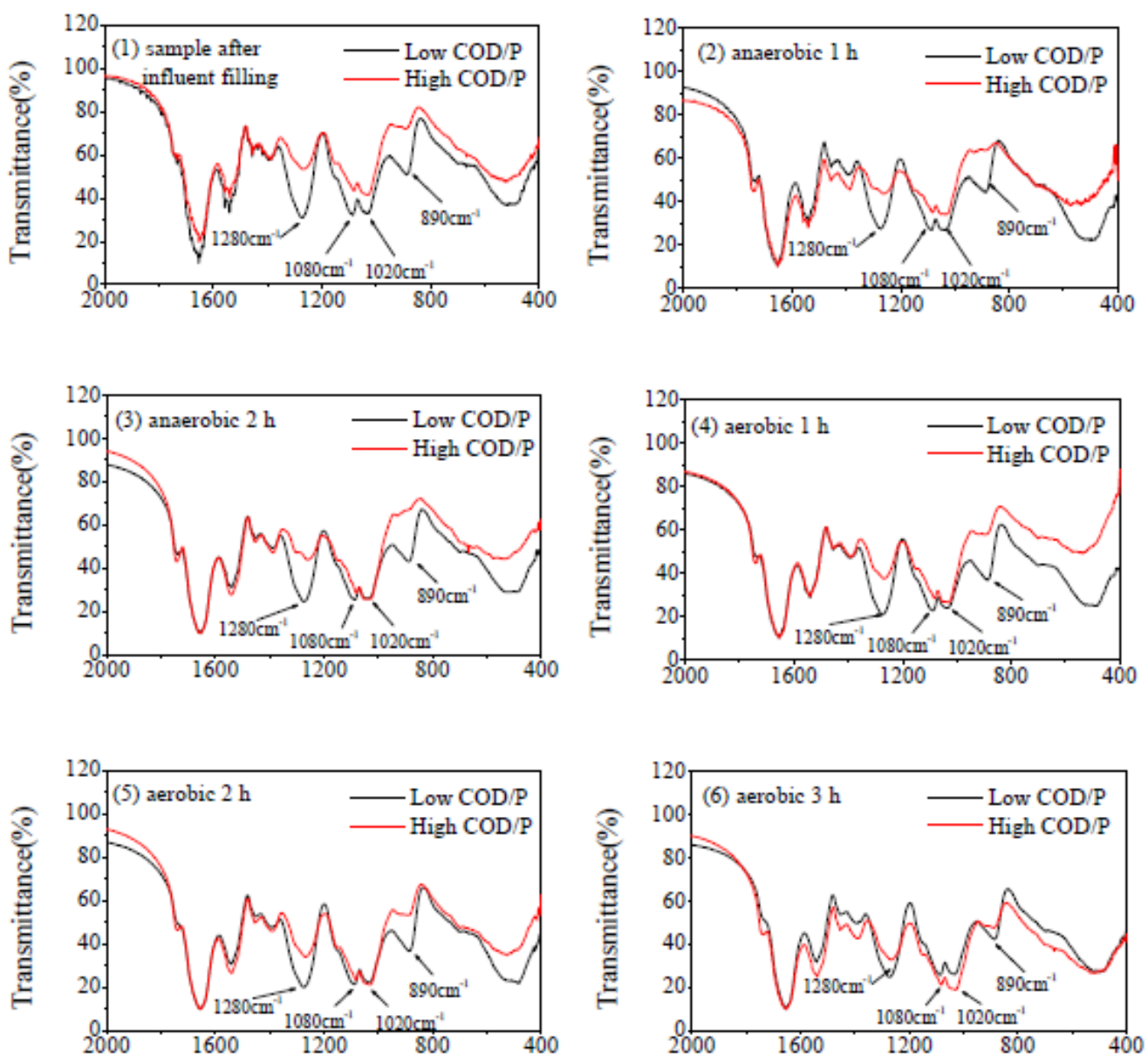

Fig. 2 Comparison of the FTIR spectra of the sludge samples from two reactors at different COD/P ratios 
The variation of COD and orthophosphate concentration of the reactor at high $\mathrm{COD} / \mathrm{P}$ ratio was shown in Fig. 1b. After the influent was filled into the reactor, COD concentration was $201.4 \pm 16.4 \mathrm{mg} / \mathrm{L}$ and orthophosphate was $2.1 \pm 0.1 \mathrm{mg} / \mathrm{L}$. At the end of the anaerobic phase COD concentration decreased to $36.8 \pm 3.0 \mathrm{mg} / \mathrm{L}$ and orthophosphate concentration increased to $4.2 \pm 0.4 \mathrm{mg} / \mathrm{L}$. It implicated that acetate was consumed in the anaerobic phase, and a small quantity of orthophosphate was transformed from poly-P by microorganisms such as PAOs. In the subsequent aerobic phase COD concentration did not vary substantially, and the orthophosphate decreased to $0.5 \pm 0.04 \mathrm{mg} / \mathrm{L}$, which implicated that the orthophosphate was utilized by the microorganisms.

3.2 Characterization of the sludge samples using FTIR spectroscopyAs shown in Fig. 2, the sludge sample from the reactor at low $\mathrm{COD} / \mathrm{P}$ ratio showed high infrared absorption at $890 \mathrm{~cm}^{-1}$, and similar intensity of two peaks at $1020 \mathrm{~cm}^{-1}$ and $1080 \mathrm{~cm}^{-1}$. The sludge sample from the reactor at high $\mathrm{COD} / \mathrm{P}$ ratio showed weak absorption of the infrared peak at $890 \mathrm{~cm}^{-1}$, and the infrared absorption at $1020 \mathrm{~cm}^{-1}$ was stronger than that at $1080 \mathrm{~cm}^{-1}$.

The infrared data between $840 \mathrm{~cm}^{-1}$ and $1200 \mathrm{~cm}^{-1}$ was selected and analyzed with principal component analysis (PCA). As shown in Fig. 3, two components was extracted and projected to principal component correlation figure $^{[11]}$. Circle-shaped symbol represent the sludge sample from the reactor at low $\mathrm{COD} / \mathrm{P}$ ratio and cross-shape symbol represent those at high $\mathrm{COD} / \mathrm{P}$ ratio. It is clearly seen that the samples from the high phosphorus loading reactor accumulated below and the samples from the low phosphorus loading reactor accumulated at the top. The difference in the FTIR spectra between the two sets of samples resulted in the difference in the principal components projection, which implicated that the difference between the FTIR spectra of the sludge sample could be recognized by principal component projection method.

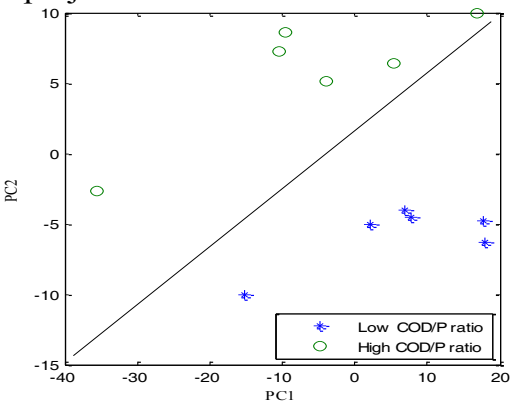

Fig. 3 Principal component projection of the FTIR spectra data of the sample from two bioreactors at different $\mathrm{COD} / \mathrm{P}$ ratios
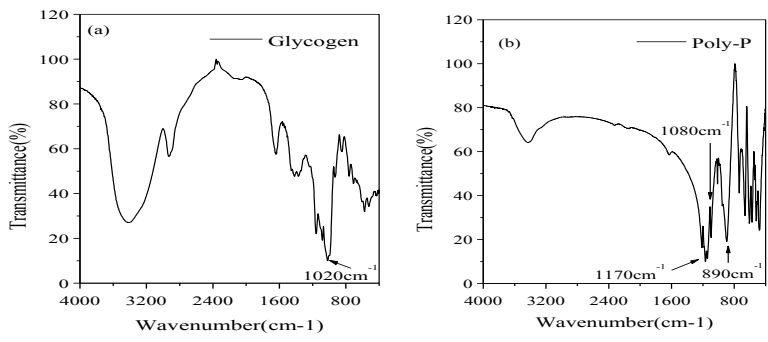

Fig. 4 The FTIR spectra of standards: (a) glycogen; (b) poly-P

In order to explicate the FTIR spectra difference of the sludge from the above two reactors, the FTIR spectra of glycogen and poly-P were determined and showed in Fig. 4. The maximum infrared absorption of glycogen was located in $1020 \mathrm{~cm}^{-1}$, while the maximum infrared absorption of poly-P was located in $1170 \mathrm{~cm}^{-1}$, and the infrared absorption located in $890 \mathrm{~cm}^{-1}$ and $1080 \mathrm{~cm}^{-1}$ was rather strong. As it was mentioned before, the FTIR spectra of the sludge from the phosphate-rich reactor showed the absorption of $1020 \mathrm{~cm}^{-1}$ and $1080 \mathrm{~cm}^{-1}$ was similar, and those from the low phosphate loading reactor showed the absorption of $1020 \mathrm{~cm}^{-1}$ was stronger than that of $1080 \mathrm{~cm}^{-1}$. It might be the difference in poly$\mathrm{P}$ content of the sludge from the above two reactors. The phosphate-rich influent favored the PAOs and promoted the synthesis of poly-P, while the low phosphorus loading influent restricted the growth of PAOs and limited the synthesis of poly-P.

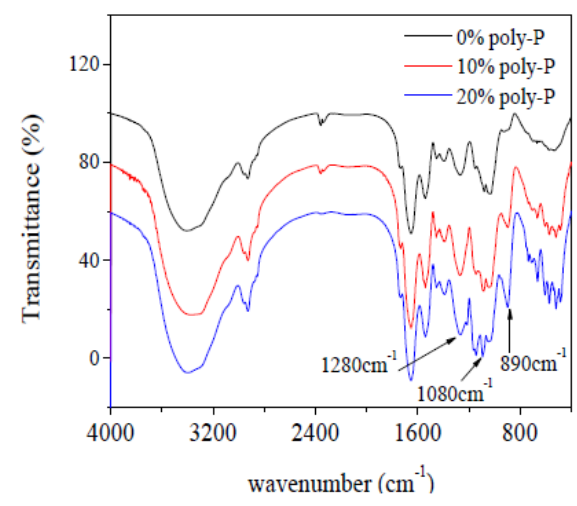

Fig. 5 Comparison of the infrared spectra of activated sludge added with different amounts of poly-P

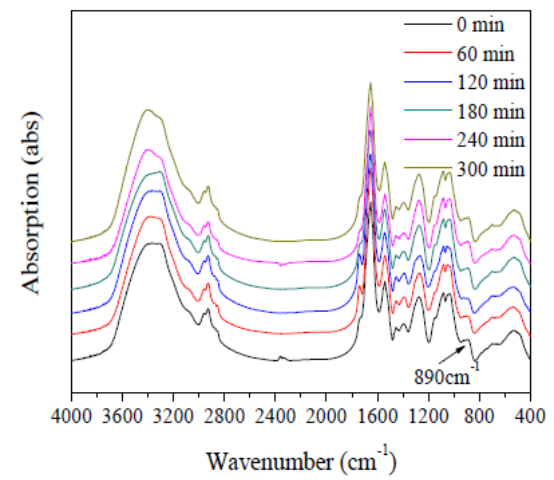

Fig. 6 The FTIR spectra of the lyophilized sludge of activated sludge added with different from phosphate-rich reactor at different sample time 
In order to validate the contribution of poly-P, different amounts of poly-P was added to three samples of the same sludge. As shown in Fig. 5, the added amounts accounted for $0 \%, 10 \%$ and $20 \%$ mass percentage respectively. Compared with the spectrum of the sludge with no poly-P addition, the spectra added with poly-P showed significantly increase at $890 \mathrm{~cm}^{-1}$. In addition, the infrared absorption at $1080 \mathrm{~cm}^{-1}$ and 1280 $\mathrm{cm}^{-1}$ increased significantly after the sludge was added with poly-P. However, they are close and overlapped with other infrared peaks. Thus, the infrared peak at 890 $\mathrm{cm}^{-1}$ was selected as the characteristic peak of poly-P.was used to eliminate the variations in the scattering, diffraction, and refraction properties of the samples as the IR beam passed through the sample. The normalization function was used to correct for differences in spectral absorbance due to different sample thicknesses within the same deposit. Normalization was performed to the protein I band because there was little spectral contribution from poly-P in this spectral region ${ }^{[9]}$.

Since the infrared absorption at $890 \mathrm{~cm}-1$ in the high phosphorus loading reactor was stronger than that in the low phosphorus loading reactor, and the infrared
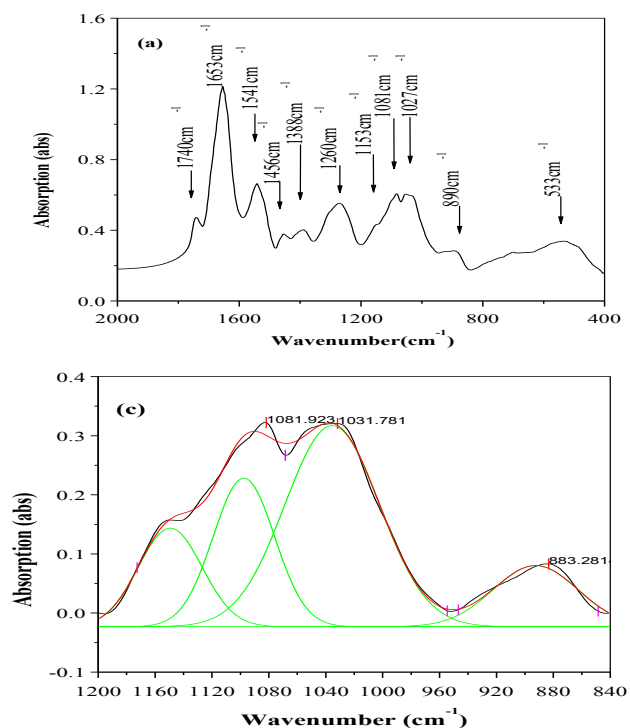

Fig. 7 The correlation between FTIR spectra and poly-P content: (a) different peaks of the lyophilized sludge; (b) Gaussian peak fitting of protein; (c) Gaussian peak fitting of poly-P; (d) correlation curve between the ratios of poly-P versus protein I integration area and the poly-P contents of the sludge

\section{Conclusions}

Poly-P can be qualified with FTIR spectra of lyophilized sludge during the EBPR process. The infrared peak at $890 \mathrm{~cm}^{-1}$ was attributed to intracellular poly-P. The peak intensity implicated the content of intracellular poly-P. Gaussian peak fitting method could be used to separate the PHA, amino I, amino II and poly-P peaks. Their integrated peak areas could be acquired respectively. The peak area ratios of poly-P versus amino I were correlated to the intracellular poly-P contents, and their correlation coefficient was amount to 0.960 . The predicted value was in good accordance with the analyzed value, and it

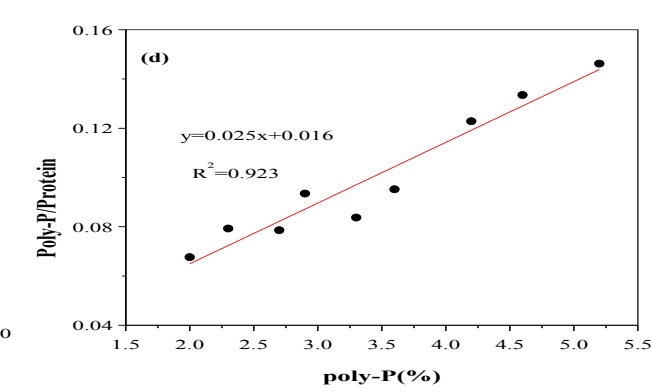

absorption at $890 \mathrm{~cm}^{-1}$ declined in the anaerobic phase and increased in the aerobic phase, we could conclude that the infrared peak was originated from the contribution of poly-P in the sludge.

Thus, as shown in Fig. 6, the variation of poly-P contents could be seen from the variation of the infrared peak intensities at $890 \mathrm{~cm}^{-1}$ after the treatment of baseline correction and normalization. They decreased in the anaerobic phase and increased in the aerobic phase, which implicated that the poly-P was hydrolyzed during the anaerobic phase and synthesized in the aerobic phase.

As shown in Fig. 7b, the peak of PHA, protein I and protein II was located in the $1740 \mathrm{~cm}^{-1}, 1653 \mathrm{~cm}-1$ and $1541 \mathrm{~cm}^{-1}$ respectively. Gaussian peak fitting method could separate them completely and their integrated area of the infrared spectra could be acquired ${ }^{[10,14]}$. Similarly, the peak of poly-P, which was located in $890 \mathrm{~cm}^{-1}$, was separated and integrated. Since the protein content per cell does not vary substantially for a wide range of intracellular storage contents, the peak area of protein I could be integrated as inner standards ${ }^{[9]}$. Thus, the infrared peak area ratios of poly-P versus protein I were correlated with the poly-P contents in the sludge as shown in Fig.7d.

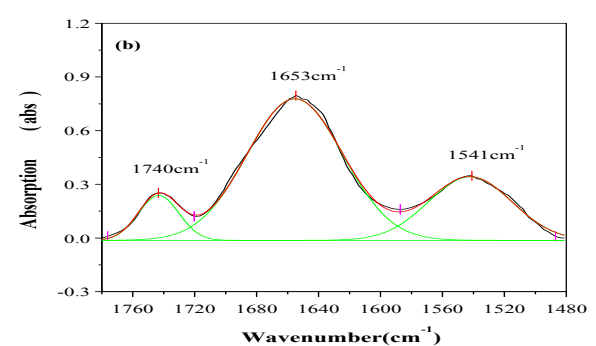

could be used in the rapid quantification of poly-P content in the activated sludge of EBPR process.

\section{Acknowledgement}

This work was supported by NSFC (51978003), Major science and technology project of Anhui Province (Grant No.17030801028), Anhui Key Project of Research and Development Plan (Grant No.1704a0902006), Anhui Natural Science Foundation Project (1908085ME141, KJ2019JD09). 


\section{References}

1. Mino, T., Van Loosdrecht, M.C.M., Heijnen, J.J. Microbiology and biochemistry of the enhanced biological phosphate removal process. Water Res. 32,3193(1998).

2. Oehmen, A., Lemos, P.C., Carvalho, G., Yuan, Z.G., Keller, J., Blackall, L.L. Reis, M.A.M. Advances in enhanced biological phosphorus removal: From micro to macro scale. Water Res. 41,2271(2007).

3. Oehmen A., Saunders A.M., Vives M.T., Yuan Z.G., Keller J. Competition between polyphosphate and glycogen accumulating organisms in enhanced biological phosphorus removal systems with acetate and propionate as carbon sources. J. Biotechnol. 123,22(2006).

4. Streichan M., Golecki J.R., Schon G. Polyphosphate-accumulating bacteria from sewage plant with different processes of biological phosphorus removal. FEMS Microbiol. Ecol.73,113(1990).

5. Zhou Y.X., Qian Y., Gu X.S. Study on the mechanism of biological phosphorus removal. Acta Scien. Circum. 13,193(1993).

6. Dou J.F., Luo G.Y., Liu X. The metabolic mechanism of anaerobic phosphorus release and its kinetic analysis during biological phosphorus removal process. Acta Scien. Circum. 25,1164(2005).

7. Majed N., Matthaus C., Diem, M., Gu A.Z. Evaluation of Intracellular Polyphosphate Dynamics in Enhanced Biological Phosphorus Removal Process using Raman Microscopy. Environ. Sci. Technol. 43,5436(2009).

8. Naumann D., Helm D., Labischinski H. Microbiological Characterizations by Ft-Ir Spectroscopy. Nature 351,81(1991).

9. Kansiz M., Billman-Jacobe H., Mcnaughton D. Quantitative Determination of the Biodegradable Polymer Poly(b-hydroxybutyrate) in a Recombinant Escherichia coli Strain by Use of MidInfraredSpectroscopy and Multivariative Statistics. Appl. Environ. Microbiol. 66,3415(2000).

10. Li W.H., Mao Q.Y., Liu Y.X, Sheng G.P., Yu H.Q., Huang X.H., Liu S.G., Ling Q., Yan G.B. Analysis of poly- $\beta$-hydroxyalkonates (PHA) during the enhanced biological phosphorus removal process using FTIR spectra. Spectroscopy and Spectral Analysis. 34(2014).

11. Astel A., Tsakovski S., Barbieri P., Simeonov V. Comparison of self-organizing maps classification approach with cluster and principal components analysis for large environmental data sets. Water Res. 41,4566(2007).

12. Lu H.B., Oehmen A., Virdis B., Keller J., Yuan Z.G. Obtaining highly enriched cultures of Candidatus Accumulibacter phosphates through alternating carbon sources. Water Res. 40,3838(2006).
13. APHA, Standard Methods for the Examination of Water and Wastewater, 19th ed. American Public Health Association, Washington, DC (1995). 